\title{
Synthesis of Soluble Polythiophene Partially Containing 3,4-Ethylenedioxythiophene and 3-Hexylthiophene by Polycondensation
}

\author{
Ichiro Imae*, Hitoshi Sagawa, Takahiro Mashima, Kenji Komaguchi, Yousuke Ooyama, \\ Yutaka Harima* \\ Department of Applied Chemistry, Graduate School of Engineering, Hiroshima University, Higashi-Hiroshima, \\ Japan \\ Email: ${ }^{*}$ imae@hiroshima-u.ac.jp, ${ }^{*}$ harima@mls.ias.hiroshima-u.ac.jp
}

Received 18 June 2014; revised 21 July 2014; accepted 1 August 2014

Copyright (C) 2014 by authors and Scientific Research Publishing Inc.

This work is licensed under the Creative Commons Attribution International License (CC BY). http://creativecommons.org/licenses/by/4.0/

cC) (7) Open Access

\begin{abstract}
A novel poly(quinquethiophene) partially containing 3,4-ethylenedioxythiophene (EDOT) and 3hexylthiophene, poly(3,3"'-dihexyl-3',4',3"',4"'-diethylenedioxy-2,2':5',2":5",2'":5'",2'"'-quinquethiophene), was synthesized by three types of polycondensations. Among them, direct $\mathrm{C}-\mathrm{H}$ coupling reaction gave the polymer with the highest molecular weight. The resulting polymer was soluble in common organic solvents. Absorption and fluorescence spectra of the polymer showed a remarkable red-shift compared with the corresponding monomer due to the expansion of effective $\pi$-conjugation length.
\end{abstract}

Keywords

Polycondensation, Polythiophene, Ethylenedioxythiophene, Alkylthiophene, Solubility

\section{Introduction}

Since the late 1970s, $\pi$-conjugated polymers have attracted a great deal of attention from many researchers, especially in the field of plastic electronics [1]-[5]. Among them, polythiophenes have been well investigated as the most significant class of $\pi$-conjugated polymers. Poly(3,4-ethylenedioxythiophene) (PEDOT) is one of the most popular polythiophene derivatives and has excellent properties such as stability of the oxidized state, moderate band-gap energy, low oxidation potential, and optical transparency in the visible spectral region [5]-[11]. These properties result from the synergistic associations of the strong donor effect of the ethylenedioxy groups

"Corresponding authors.

How to cite this paper: Imae, I., Sagawa, H., Mashima, T., Komaguchi, K., Ooyama, Y. and Harima, Y. (2014) Synthesis of Soluble Polythiophene Partially Containing 3,4-Ethylenedioxythiophene and 3-Hexylthiophene by Polycondensation. Open Journal of Polymer Chemistry, 4, 83-93. http://dx.doi.org/10.4236/ojpchem.2014.43010 
with the propensity of 3,4-ethylenedioxythiophene (EDOT) to develop noncovalent intramolecular S-O interaction [12]-[17]. This S-O interaction, on the other hand, leads to a rigid polymer backbone to reduce the solubility in solvents. Thus, PEDOT obtained by electrochemical oxidation of EDOT is insoluble in common organic solvents.

Until now, several types of polythiophenes partially containing EDOT have been synthesized and successfully applied to electrochromic devices because of the stable nature of the oxidized state [18]-[24]. However, there are few reports on the characterization of these polymers and their charge transport properties. Recently, we have synthesized a polythiophene partially containing EDOT unit in the repeat unit, poly(3',4'-ethylenedioxy-2,2':5',2"terthiophene) (polyTET), by electrolytic polymerization of the EDOT-containing terthiophene, 3',4'-ethylenedioxy-2,2':5',2"-terthiophene (TET) (Scheme 1) [25]. The resulting polymer was found to be soluble in dimethylsuldoxide (DMSO), tetrahedrofuran (THF) and dimethylformamide (DMF), and could be characterized by ${ }^{1} \mathrm{H}$ NMR and mass spectroscopies, and gel permeation chromatography (GPC). The electrical conductivities of polyTET were measured as a function of oxidation levels, and the highest conductivity was found to be comparable to that of polythiophene obtained by the electrolytic polymerization of unsubstituted thiophene. However, the molecular weight of the polymer was not so high because the cationic species formed by electrochemical oxidation were stable and could not be polymerized, and the film-forming property was very poor.

Poly(arylene)s including polythiophenes have been synthesized not only by electrolytic polymerizations [26], but also by chemically oxidative polymerizations [27] [28] and organometallic polycondensations [29]. Since the polycondensations afford the polymers with well-controlled bonding between monomeric units, many types of polycondensations have been developed.

In this paper, three types of polycondensations using (1) Suzuki, (2) Stille, and (3) direct C-H coupling reactions were investigated to obtain a novel EDOT-containing polythiophene, poly(3,3"'-dihexyl-3',4',3"',4"'diethylenedioxy-2,2':5',2":5",2"':5"',2"'-quinquethiophene) (polyHE5T) (Figure 1).

\section{Experimental}

\subsection{Materials and Instrumentation}

$n$-Hexane, toluene, THF, dimethylacetamide (DMAc), dichloromethane, diethyl ether, acetic acid (AcOH), and acetonitrile were purified by conventional methods and used immediately after purification. All reagents and organic solvents were purchased from Tokyo Chemical Industry, Wako Pure Chemical Industries, Sigma-Aldrich, Kanto Chemical, and Nacalai Tesque and were used without further purification. 2-Bromo-3-hexylthiophene was synthesized from 3-bromothiophene according to the literature [30] [31]. $N$-Bromosuccinimide (NBS) was purified by recrystallization from benzene and dried under vacuum.

${ }^{1} \mathrm{H}$ NMR spectra were recorded by a $500 \mathrm{MHz}$ spectrometer (Varian Inc., NMR System 500). IR spectra were taken on a Perkin Elmer Spectrum One FT-IR spectrophotometer by ATR method. Molecular weights of the resulting polymers were analyzed by a GPC coupled with an UV detector (Shimadzu Corp., SPD-10A). Combination of Shodex KF-801 (30 cm, exclusion limit: $M_{\mathrm{n}}=1.5 \times 10^{3}$, polystyrene) KF-802 (30 cm, exclusion limit: $M_{\mathrm{n}}=5.0 \times 10^{3}$, polystyrene) and KF-803L (30 cm, exclusion limit: $M_{\mathrm{n}}=7.0 \times 10^{4}$, polystyrene) columns (linear calibration down to $M_{\mathrm{n}}=100$ ) were used for molecular weight analysis with THF $\left(1.0 \mathrm{dm}^{3} \cdot \mathrm{min}^{-1}\right)$ as an eluent. Measurements of mass spectroscopy and the elemental analysis were made using a High Performance Gas Chromatograph-Time-of-Flight Mass Spectrometer (JEOL, JMS-T100GCV (Accu TOFGCv 4G)) and an Elemental Analyzer (PerkinElmer, 2400 Series II CHNS/O), respectively. UV-vis absorption and fluorescence spectra were measured by a Shimadzu UV-3150 spectrophotometer and a Hitachi F-4500 spectrophotometer, respectively. Fluorescence quantum yields $(\Phi)$ were determined by a Hamamatsu C9920-01 equipped with CCD by using a calibrated integrating sphere system.

\subsection{Monomer Synthesis}

The synthetic routes of the monomers are shown in Scheme 2 and the detailed synthetic processes are described below.

\subsubsection{Synthesis of 3,4,3",4"'-Diethylenedioxy-2,2':5',2"-terthiophene (E3T)}

To a solution of 3,4-ethylenedioxythiophene $(2.8 \mathrm{~g}, 20 \mathrm{mmol})$ in THF $(60 \mathrm{~mL})$ at $-78^{\circ} \mathrm{C}$ was added $15 \mathrm{~mL}(24$ mmol) of $n$-butyllithium ( $1.65 \mathrm{M}$ in $n$-hexane) by syringe. The mixture was stirred at $-78^{\circ} \mathrm{C}$ for $30 \mathrm{~min}$. 


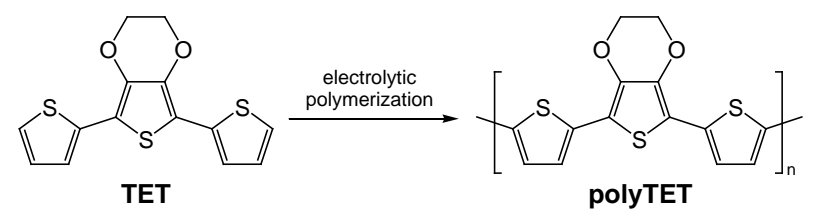

Scheme 1. Synthesis of polyTET by electrolytic polymerization.

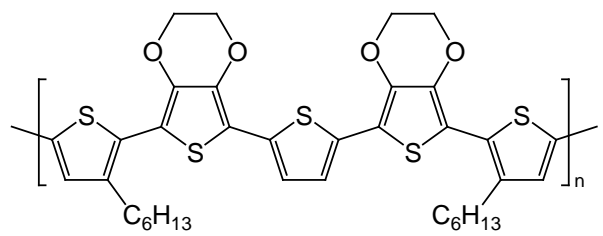

Figure 1. Chemical structure of polyHE5T.
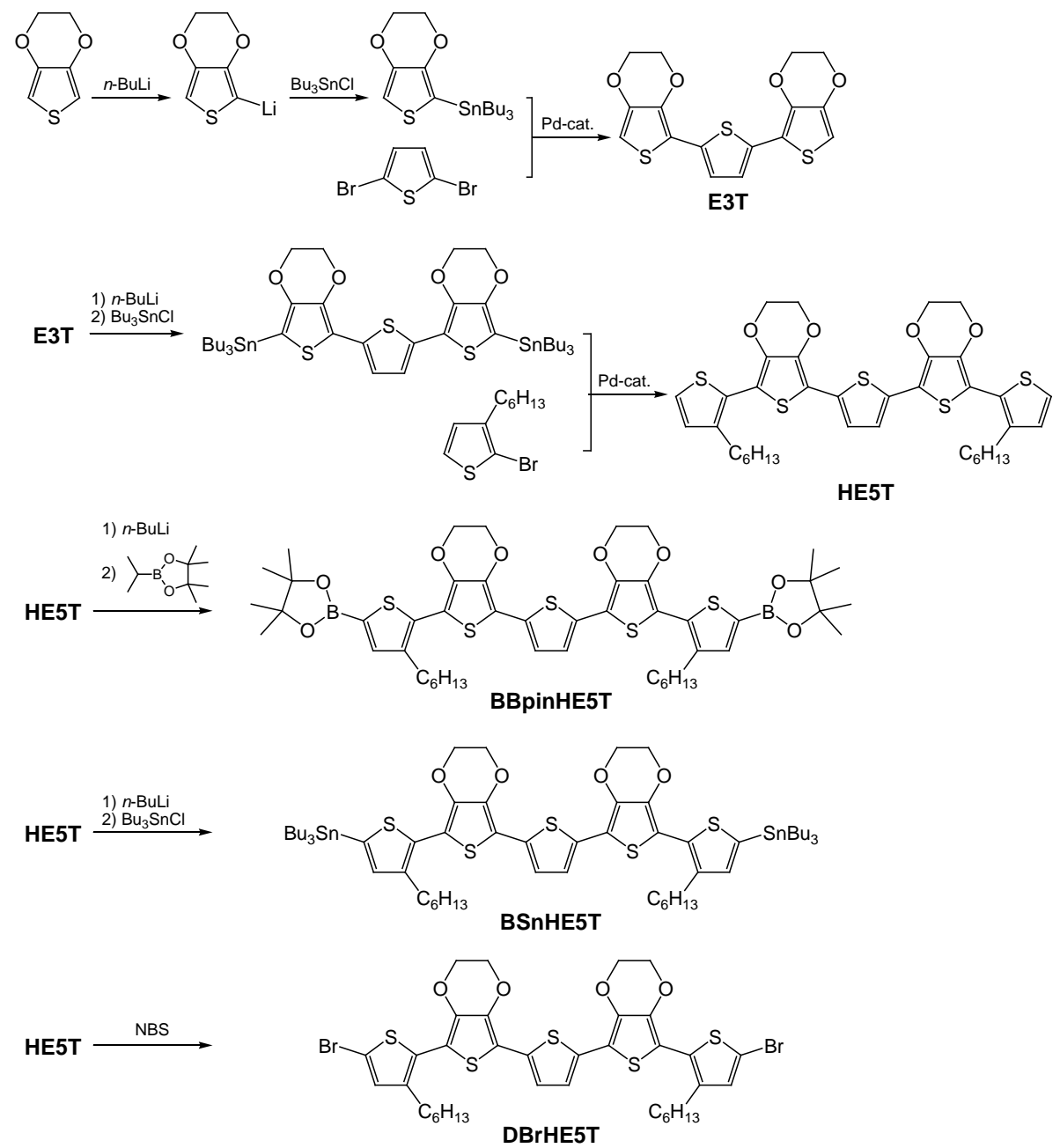

Scheme 2. Synthetic route of monomers.

Tri(n-butyl)tin chloride (5.7 g, $18 \mathrm{mmol})$ was added to the solution, and the resulting mixture was stirred at $-78^{\circ} \mathrm{C}$ for $30 \mathrm{~min}$, warmed to room temperature, and stirred further for $3 \mathrm{~h}$. The solvent was removed via rotary evaporation, and $n$-hexane was added to the residue. The soluble fraction was extracted by filtration. The filtrated solution was added to a solution of tetrakis(triphenylphosphine)palladium (720 mg, $0.6 \mathrm{mmol}$ ) and 2,5dibromothiophene $(1.8 \mathrm{~g}, 7.6 \mathrm{mmol})$ in DMF $(50 \mathrm{~mL})$. The solution was stirred at $100^{\circ} \mathrm{C}$ for $12 \mathrm{~h}$. The mixture 
was poured into sat.aq. $\mathrm{NH}_{4} \mathrm{Cl}(400 \mathrm{~mL})$ and extracted with dichloromethane. The extract was then successively washed with water. After being dried over anhydrous $\mathrm{Na}_{2} \mathrm{SO}_{4}$, the solvent was evaporated, and the residue was purified by column chromatography on silica gel with a mixed solvent of $n$-hexane and ethyl acetate $(v / v=3 / 2)$ to afford a yellow solid (2.7 g, $7.3 \mathrm{mmol}$ ). Yield: $96 \% .{ }^{1} \mathrm{H}$ NMR (500 MHz, $\mathrm{CDCl}_{3}, \delta$, ppm): $4.23-4.37$ (m, 8H, $\mathrm{OCH}_{2} \mathrm{CH}_{2} \mathrm{O}$ ), 6.21 (s, 2H, thienyl-H), 7.12 (s, 2H, thienyl-H). FTIR (ATR, $v, \mathrm{~cm}^{-1}$ ): 3113, 3103, 3067, 2979, 2924, 2871, 1530, 1481, 1434, 1362, 1329, 1165, 1137, 1071, 1053, 1017, 968, 905, 881, 802, 710, 678. Anal. Calcd for $\mathrm{C}_{16} \mathrm{H}_{12} \mathrm{O}_{4} \mathrm{~S}_{3}$ : C, 52.73; H, 3.32; S, 26.39. Found: C, 53.11; H, 3.30; S, 25.53. HRMS (EI) m/z calcd for $\mathrm{C}_{16} \mathrm{H}_{12} \mathrm{O}_{4} \mathrm{~S}_{3} 363.9898\left(\mathrm{M}^{+}\right)$, found 363.9890( $\left(\mathrm{M}^{+}\right)$.

\subsubsection{Synthesis of 3,3"'--Dihexyl-3',4',3"',4"'-diethylenedioxy-2, 2':5',2":5",2"':5"',2"'"- quinquethiophene (HE5T)}

To a solution of E3T (1.5 g, $4.0 \mathrm{mmol}$ ) in THF ( $40 \mathrm{~mL}$ ) at $-78^{\circ} \mathrm{C}$ was added $2.7 \mathrm{~mL}$ ( $4.4 \mathrm{mmol}$ ) of $n$-butyllithium (1.65 $\mathrm{M}$ in $n$-hexane) by syringe. The mixture was stirred at $-78^{\circ} \mathrm{C}$ for $30 \mathrm{~min}$. Tri( $n$-butyl)tin chloride (1.4 g, $4.3 \mathrm{mmol}$ ) was added to the solution, and the resulting mixture was stirred at $-78^{\circ} \mathrm{C}$ for $30 \mathrm{~min}$, warmed to room temperature, and stirred further for $1 \mathrm{~h}$. The solvent was removed via rotary evaporation, and $n$-hexane was added to the residue. The soluble fraction was extracted by filtration. The filtrated solution was added to a solution of tetrakis(triphenylphosphine)palladium $(200 \mathrm{mg}, 0.17 \mathrm{mmol})$ and 2-bromo-3-hexylthiophene $(1.8 \mathrm{~g}, 7.2$ $\mathrm{mmol}$ ) in DMF ( $40 \mathrm{~mL})$. The solution was stirred at $100^{\circ} \mathrm{C}$ for $12 \mathrm{~h}$. The mixture was poured into sat.aq. $\mathrm{NH}_{4} \mathrm{Cl}$ $(400 \mathrm{~mL})$ and extracted with dichloromethane. The extract was then successively washed with water. After drying over anhydrous $\mathrm{Na}_{2} \mathrm{SO}_{4}$, the solvent was evaporated, and the residue was purified by column chromatography on silica gel with a mixed solvent of $n$-hexane and dichloromethane $(v / v=2 / 3)$ to afford a dark red solid (1.6 g, $2.3 \mathrm{mmol}$ ). Yield: 58\%. ${ }^{1} \mathrm{H}$ NMR (500 MHz, acetone- $\mathrm{d}_{6}, \delta$, ppm): 0.88 (t, $J=7.03 \mathrm{~Hz}, 6 \mathrm{H}, \mathrm{CH}_{3}$ ), 1.25 $1.42\left(\mathrm{~m}, 12 \mathrm{H},\left(\mathrm{CH}_{2}\right)_{3} \mathrm{CH}_{3}\right), 1.60$ - $1.68\left(\mathrm{~m}, 4 \mathrm{H}\right.$, thienyl- $\left.\mathrm{CH}_{2} \mathrm{CH}_{2}\right), 2.76\left(\mathrm{t}, J=7.77 \mathrm{~Hz}, 4 \mathrm{H}\right.$, thienyl- $\left.\mathrm{CH}_{2}\right)$, 4.38 $4.51\left(\mathrm{~m}, 8 \mathrm{H}, \mathrm{OCH}_{2} \mathrm{CH}_{2} \mathrm{O}\right.$ ), 7.02 (d, $J=5.22 \mathrm{~Hz}, 2 \mathrm{H}$, thienyl- $\boldsymbol{H}$ ), 7.23 (s, 2H, thienyl- $\boldsymbol{H}$ ), 7.43 (d, $J=5.22 \mathrm{~Hz}$, 2H, thienyl-H). FTIR (ATR, $v, \mathrm{~cm}^{-1}$ ): 3097, 3077, 3061, 2953, 2924, 2868, 2854, 1527, 1491, 1438, 1360, 1322, 1096, 1081, 1062, 1013, 959, 914, 874, 830, 782, 689, 650, 478. Anal. Calcd for $\mathrm{C}_{36} \mathrm{H}_{40} \mathrm{O}_{4} \mathrm{~S}_{5}$ : C, 62.03; H, 5.78; S, 23.00. Found: C, 61.88; H, 5.58; S, 22.67. HRMS (EI) m/z calcd for $\mathrm{C}_{36} \mathrm{H}_{40} \mathrm{O}_{4} \mathrm{~S}_{5} 696.1530\left(\mathrm{M}^{+}\right.$), found $696.1539\left(\mathrm{M}^{+}\right)$.

\subsubsection{Synthesis of 2,5'"'-Bis(4,4,5,5-tetramethyl-1,3,2-dioxaborolan-2-yl)-3,3"'"-dihexyl- \\ 3',4',3"',4"'-diethylenedioxy-2,2':5',2":5",2"':5"',2"'"-quinquethiophene (BBpinHE5T)}

To a solution of HE5T $(0.48 \mathrm{~g}, 0.69 \mathrm{mmol})$ in THF $(7 \mathrm{~mL})$ at $-78^{\circ} \mathrm{C}$ was added $0.8 \mathrm{~mL}(2.1 \mathrm{mmol})$ of $n$-butyllithium (2.6 $\mathrm{M}$ in $n$-hexane) by syringe. The mixture was stirred at $-7^{\circ} \mathrm{C}$ for $1 \mathrm{~h}$. 2-Isopropoxy-4,4,5,5-tetramethyl1,3,2-dioxaborolane $\left(0.32 \mathrm{~g}, 1.7 \mathrm{mmol}\right.$ ) was added to the solution, and the resulting mixture was stirred at $-78^{\circ} \mathrm{C}$ for $90 \mathrm{~min}$, warmed to room temperature, and stirred further for $90 \mathrm{~min}$. The solvent was removed via rotary evaporation, and $n$-hexane was added to the residue. The mixture was poured into sat.aq. $\mathrm{NH}_{4} \mathrm{Cl}(400 \mathrm{~mL})$ and extracted with dichloromethane. The extract was then successively washed with water. After being dried over anhydrous $\mathrm{Na}_{2} \mathrm{SO}_{4}$, the solvent was evaporated, and the residue was purified by preparative GPC to afford a dark red and viscous liquid (90 mg, $0.11 \mathrm{mmol}$ ). Yield: $16 \%$. ${ }^{1} \mathrm{H}$ NMR (500 MHz, acetone- $\mathrm{d}_{6}, \delta$, ppm): 0.89 (t, $J$ $\left.=6.91 \mathrm{~Hz}, 6 \mathrm{H}, \mathrm{CH}_{3}\right), 1.30-1.44\left(\mathrm{~m}, 12 \mathrm{H},\left(\mathrm{CH}_{2}\right)_{3} \mathrm{CH}_{3}\right), 1.33\left(\mathrm{~s}, 24 \mathrm{H}, \mathrm{C}\left(\mathrm{CH}_{3}\right)_{2}\right), 1.64-1.71(\mathrm{~m}, 4 \mathrm{H}$, thienyl$\mathrm{CH}_{2} \mathrm{CH}_{2}$ ), 2.76 - 2.80 (m, 4H, thienyl- $\mathrm{CH}_{2}$ ), 4.42 - 4.52 (m, 8H, OCH $\mathrm{CH}_{2} \mathrm{O}$ ), 7.26 (s, 2H, thienyl-H), 7.43 (s, $2 \mathrm{H}$, thienyl-H).

\subsubsection{Synthesis of 2, 5'"'-Bis(tributylstannyl)-3,3"'"-dihexyl-3',4',3"',4"'-diethylenedioxy- $2,2 ': 5$ ',2":5",2"':5"',2"'"-quinquethiophene (BSnHE5T)}

To a solution of HE5T ( $80 \mathrm{mg}, 0.11 \mathrm{mmol})$ in THF $(3 \mathrm{~mL})$ at $-78^{\circ} \mathrm{C}$ was added $0.14 \mathrm{~mL}(0.23 \mathrm{mmol})$ of $n$-butyllithium (1.65 $\mathrm{M}$ in $n$-hexane) by syringe. The mixture was stirred at $-78^{\circ} \mathrm{C}$ for $1 \mathrm{~h}$. Tri ( $n$-butyl) tin chloride $\left(72 \mathrm{mg}, 0.22 \mathrm{mmol}\right.$ ) was added to the solution, and the resulting mixture was stirred at $-78^{\circ} \mathrm{C}$ for $2.5 \mathrm{~h}$, warmed to room temperature, and stirred further for $1 \mathrm{~h}$. The solvent was removed via rotary evaporation, and $n$-hexane was added to the residue. The soluble fraction was extracted by filtration and the solvent was removed in vacuo. Because BSnHE5T is unstable, it was used for polymerization without purification. ${ }^{1} \mathrm{H}$ NMR (500 MHz, acetone- $\left.\mathrm{d}_{6}, \delta, \mathrm{ppm}\right): 0.90$ (t, $\left.J=7.34 \mathrm{~Hz}, 18 \mathrm{H}, \mathrm{Sn}\left(\mathrm{CH}_{2}\right)_{3} \mathrm{CH}_{3}\right), 0.91$ (t, $J=7.34 \mathrm{~Hz}, 6 \mathrm{H}$, thienyl- $\left.\left(\mathrm{CH}_{2}\right)_{5} \mathrm{CH}_{3}\right)$, 1.17 (t with fine coupling, $\left.J=8.10 \mathrm{~Hz}, 12 \mathrm{H}, \mathrm{SnCH}_{2}\right), 1.30-1.42\left(\mathrm{~m}, 24 \mathrm{H}\right.$, thienyl- $\left(\mathrm{CH}_{2}\right)_{2}\left(\mathrm{CH}_{2}\right)_{3} \mathrm{CH}_{3}$ and 
$\mathrm{Sn}\left(\mathrm{CH}_{2}\right)_{2} \mathrm{CH}_{2} \mathrm{CH}_{3}$ ), 1.60 - 1.71 (m, 16H, thienyl- $\mathrm{CH}_{2} \mathrm{CH}_{2}$ and $\mathrm{SnCH}_{2} \mathrm{CH}_{2}$ ), 2.80 (t, $J=7.71$, 4H, thienyl-CH ), 4.37-4.49 (m, 8H, OCH $\boldsymbol{H}_{2} \mathrm{CH}_{2} \mathrm{O}$ ), 7.09 (s, 2H, thienyl-H), 7.22 (s, 2H, thienyl-H).

\subsubsection{Synthesis of 2,5'"'-Dibromo-3,3'"'-dihexyl-3',4',3'",4"'-diethylenedioxy- \\ $2,2^{\prime}: 5$ ',2":5",2"':5"',2"'"-quinquethiophene (DBrHE5T)}

To a $\mathrm{CHCl}_{3} / \mathrm{AcOH}(50 \mathrm{~mL} / 50 \mathrm{~mL})$ solution of HE5T $(0.40 \mathrm{~g}, 0.58 \mathrm{mmol})$, a $\mathrm{CHCl}_{3} / \mathrm{AcOH}(50 \mathrm{~mL} / 50 \mathrm{~mL})$ solution of NBS $(0.21 \mathrm{~g}, 1.2 \mathrm{mmol})$ was slowly added in the dark at $0^{\circ} \mathrm{C}$. The reaction mixture was stirred in the dark at room temperature for $6 \mathrm{~h}$. The mixture solution was poured into water, and extracted two times with $\mathrm{CHCl}_{3}$ (200 mL each). The combined organic extracts were washed with aq. $\mathrm{Na}_{2} \mathrm{CO}_{3}$ and water, and dried over anhydrous $\mathrm{Na}_{2} \mathrm{SO}_{4}$. The solvent was evaporated, and the residue was purified by column chromatography on silica gel with a mixed solvent of $n$-hexane and dichloromethane $(v / v=1 / 1)$ to afford an orange powder $(0.23 \mathrm{~g}$, $0.27 \mathrm{mmol}$ ). Yield: 47\%. ${ }^{1} \mathrm{H}$ NMR (500 MHz, acetone- $\mathrm{d}_{6}, \delta$, ppm): 0.88 (t, $J=7.09 \mathrm{~Hz}, 6 \mathrm{H}, \mathrm{CH}_{3}$ ), $1.27-1.43$ (m, 12H, $\left.\left(\mathrm{CH}_{2}\right)_{3} \mathrm{CH}_{3}\right), 1.60$ - 1.67 (m, 4H, thienyl- $\mathrm{CH}_{2} \mathrm{CH}_{2}$ ), $2.75\left(\mathrm{t}, J=7.77 \mathrm{~Hz}, 4 \mathrm{H}\right.$, thienyl-C $\boldsymbol{H}_{2}$ ), 4.42 - 4.51 (m, 8H, OCH $\mathrm{CH}_{2} \mathrm{O}$ ), 7.08 (s, 2H, thienyl- $\boldsymbol{H}$ ), 7.25 (s, 2H, thienyl-H). FTIR (ATR, $v, \mathrm{~cm}^{-1}$ ): 3096, 3057, 2952, 2925, 2869, 2855, 1510, 1487, 1450, 1359, 1322, 1091, 1013, 956, 834, 780, 470. Anal. Calcd for $\mathrm{C}_{36} \mathrm{H}_{38} \mathrm{Br}_{2} \mathrm{O}_{4} \mathrm{~S}_{5}$ : C, 50.58; H, 4.48; S, 18.76. Found: C, 50.50; H, 4.39; S, 18.68. HRMS (EI) $\mathrm{m} / \mathrm{z}$ calcd for $\mathrm{C}_{36} \mathrm{H}_{38} \mathrm{Br}_{2} \mathrm{O}_{4} \mathrm{~S}_{5} 851.9740\left(\mathrm{M}^{+}\right)$, found $851.9723\left(\mathrm{M}^{+}\right)$.

\subsection{Polymer Synthesis}

PolyHE5T was synthesized by three types of polycondensation reactions shown in Scheme 3 and the detailed synthetic processes are described below.

\subsubsection{Polycondensation Using Suzuki Coupling}

BBpinHE5T (90 mg, $0.11 \mathrm{mmol}$ ), DBrHE5T (98 mg, $0.11 \mathrm{mmol}$ ), tetrakis(triphenylphosphine)palladium (7 $\mathrm{mg}, 6 \mu \mathrm{mol})$, potassium carbonate $(48 \mathrm{mg}, 0.35 \mathrm{mmol})$, and water $(0.6 \mathrm{~mL})$ were dissolved in dry THF $(3 \mathrm{~mL})$. The reaction mixture was stirred at $100^{\circ} \mathrm{C}$ for $24 \mathrm{~h}$. After it was cooled to room temperature, the mixture was poured into water. The precipitate was washed with methanol.

\subsubsection{Polycondensation Using Stille Coupling}

BSnHE5T (130 mg, $0.10 \mathrm{mmol}$ ), DBrHE5T (85 mg, $0.10 \mathrm{mmol}$ ), and tetrakis(triphenylphosphine)palladium $(12 \mathrm{mg}, 10 \mu \mathrm{mol})$ were dissolved in dry DMF $(5 \mathrm{~mL})$. The reaction mixture was stirred at $80^{\circ} \mathrm{C}$ for $10 \mathrm{~h}$. After it

(1) Suzuki coupling

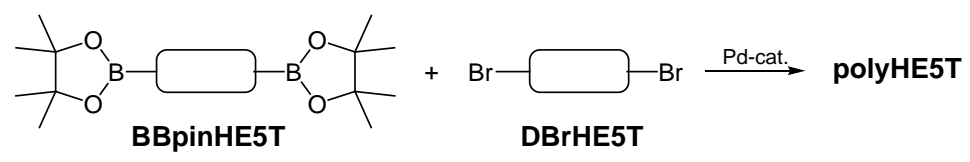

(2) Stille coupling
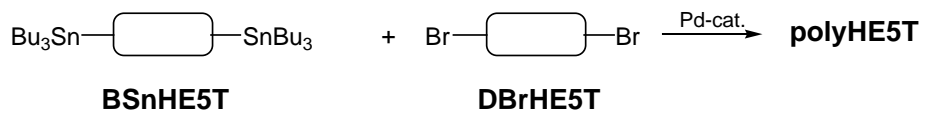

(3) direct $\mathrm{C}-\mathrm{H}$ coupling
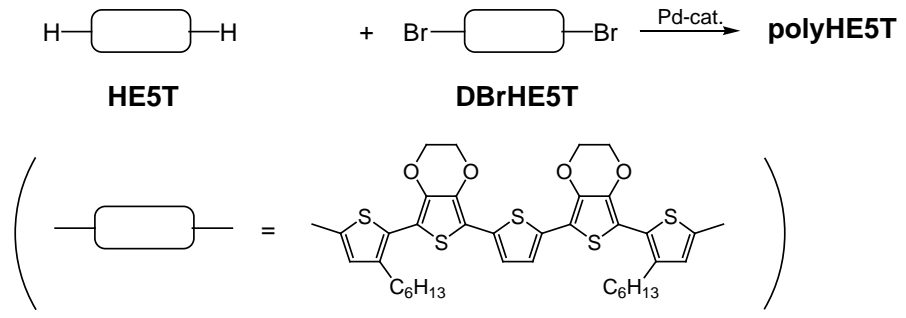

Scheme 3. Three types of polycondensations studied in this work. 
was cooled to room temperature, the mixture was poured into water. The mixture was poured into sat.aq. $\mathrm{NH}_{4} \mathrm{Cl}$ and extracted with $\mathrm{CHCl}_{3}$. The extract was then successively washed with water.

\subsubsection{Polycondensation Using Direct C-H Coupling}

HE5T (30 mg, $43 \mu \mathrm{mol}$ ), DBrHE5T (37 mg, $43 \mu \mathrm{mol})$, bis(dibenzylideneacetone)palladium (1.3 mg, $2.3 \mu \mathrm{mol})$, tris (o-methoxyphenyl)phosphine $(0.75 \mathrm{mg}, 2.1 \mu \mathrm{mol})$, pivalic acid $(6.6 \mathrm{mg}, 65 \mu \mathrm{mol})$, and cesium carbonate (28 $\mathrm{mg}, 86 \mu \mathrm{mol})$ were dissolved in dry THF $(0.5 \mathrm{~mL})$. The reaction mixture was stirred at $100^{\circ} \mathrm{C}$ for $24 \mathrm{~h}$. After it was cooled to room temperature, the mixture was poured into water. The precipitate was washed with methanol and dissolved in $\mathrm{CHCl}_{3}$. The solution was mixed with an aqueous solution of sodium diethyldithiocarbamate to remove the soluble palladium derivatives, and the mixture was stirred for $3 \mathrm{~h}$ at room temperature. The organic phase was washed with diluted hydrochloric acid and water, and dried over anhydrous $\mathrm{Na}_{2} \mathrm{SO}_{4}$. The residue was purified by reprecipitation to afford a black solid. ${ }^{1} \mathrm{H}$ NMR (500 MHz, THF-d $\mathrm{d}_{8}, \delta$, ppm): $0.87-0.97$ (br, 6H, $\mathrm{CH}_{3}$ ), 1.25 - 1.50 (br, 12H, $\left.\left(\mathrm{CH}_{2}\right)_{3} \mathrm{CH}_{3}\right), 1.60$ - 1.68 (br, 4H, thienyl- $\left.\mathrm{CH}_{2} \mathrm{CH}_{2}\right), 2.72$ - 2.87 (br, 4H, thienyl- $\mathrm{CH}_{2}$ ), 4.26 - 4.48 (br, 8H, OCH $\boldsymbol{H}_{2} \mathrm{CH}_{2} \mathrm{O}$ ), 6.90 - 7.38 (br, 4H, thienyl-H). FTIR (ATR, $v, \mathrm{~cm}^{-1}$ ): 3061, 2951, 2922, 2866, 2853, 1482, 1435, 1359, 1084, 1014, 956, 927, 887, 876, 787, 690, 488.

\section{Results and Discussion}

\subsection{Synthesis of Monomers}

Scheme 2 shows a synthetic route of HE5T and DBrHE5T. E3T was synthesized by Stille coupling between 2,5-dibromothiophene and 2-(tributylstannyl)-3,4-ethylenedioxythiophene prepared from EDOT, and its yield was 96\%. 2,5"-Bis (tributylstannyl)-substituted E3T was synthesized and coupled with 2-bromo-3-hexylthiphene to give HE5T with reasonable yield. Bromination of HE5T with NBS gave DBrHE5T, but its yield was not so high (47\%). The plausible reason of the low yield is that HE5T or DBrHE5T will decomposed by $\mathrm{Br}_{2}$ formed during the reaction [32].

\subsection{Polycondensation Methods}

To choose the polycondensation method which gives polyHE5T with the highest molecular weight, three types of polycondensations using (1) Suzuki, (2) Stille, and (3) direct C-H coupling reactions were investigated (Scheme 3).

Figure 2 shows GPC curves of as-prepared polymers obtained by three types of polycondensations. Four peaks were observed at 23.4, 21.0, 19.8, and $19.0 \mathrm{~min}$, whose retention times were ascribed to the molecular weights of monomer, dimer, trimer, and tetramer of HE5T unit. A broad shoulder peak due to component of higher molecular weight of polyHE5T was also observed from 16 to $19 \mathrm{~min}$. The intensity of the shoulder peak of a polymer prepared by direct C-H coupling was much stronger than those of polymers prepared by Suzuki and Stille coupling reactions. In the case of direct C-H coupling, the threshold value of retention time $\left(R T_{\text {th }}\right)$, where GPC curve raise up, was 16 min corresponding to the molecular weight $(M W)$ of 63,000 (polystyrene standard). On the other hand, $R T_{\mathrm{th}} \mathrm{S}$ in the case of Suzuki and Stille couplings were $16.9 \mathrm{~min}(M W=22,000)$ and 16.7 min $(M W=28,000)$, respectively. These results suggest that the molecular weight of polyHE5T prepared by direct C-H coupling is higher than those of Suzuki and Stille couplings. In the case of Suzuki and Stille couplings, bis(dioxaborolanyl)- and/or bis(trialkylstannyl)-substituted HE5Ts (BBpinHE5T and BSnHE5T in Scheme 3, respectively) were synthesized from HE5T as monomers, and coupled with DBrHE5T in stoichiometric amount. Since the stabilities of these bifunctional HE5Ts were low, their purifications were difficult. This is the reason why the molecular weights of polymers synthesized by Suzuki and Stille coupling reactions were lower than that of the polymer synthesized by direct C-H coupling reaction.

\subsection{Reaction Condition of Direct C-H Coupling}

Polycondensation reactions using direct $\mathrm{C}-\mathrm{H}$ coupling were carried out under various conditions. Table 1 summarizes the reaction conditions, and Figure 3 shows the GPC curves of as-prepared polymers obtained by these conditions.

Because $\mathrm{PCy}_{3} \cdot \mathrm{HBF}_{4}$ was reported as an effective ligand for Pd-catalyzed direct C-H coupling reaction of thiophene derivatives [33] [34], the catalytic system of $\mathrm{Pd}(\mathrm{OAc})_{2}$ with $\mathrm{PCy}_{3} \cdot \mathrm{HBF}_{4}$ was examined first (entry 1-3). 


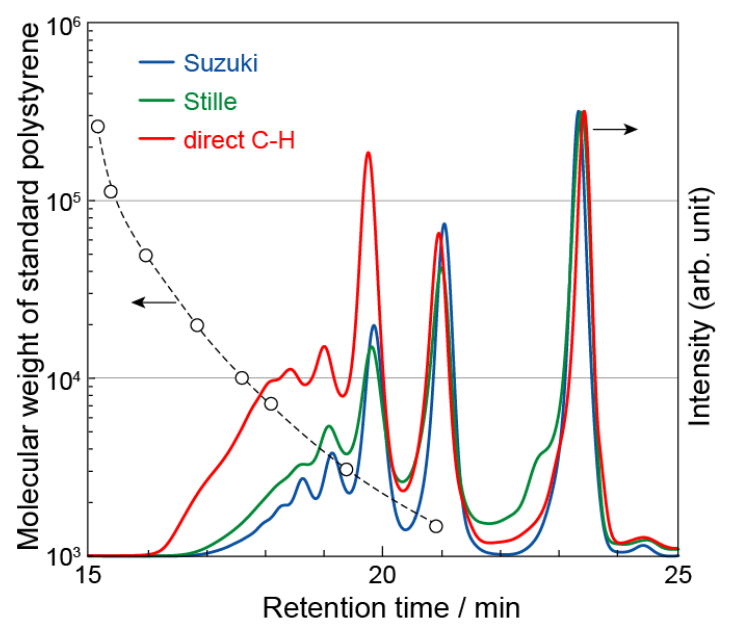

Figure 2. GPC curves of as-prepared polyHE5Ts obtained by three types of polycondensations.

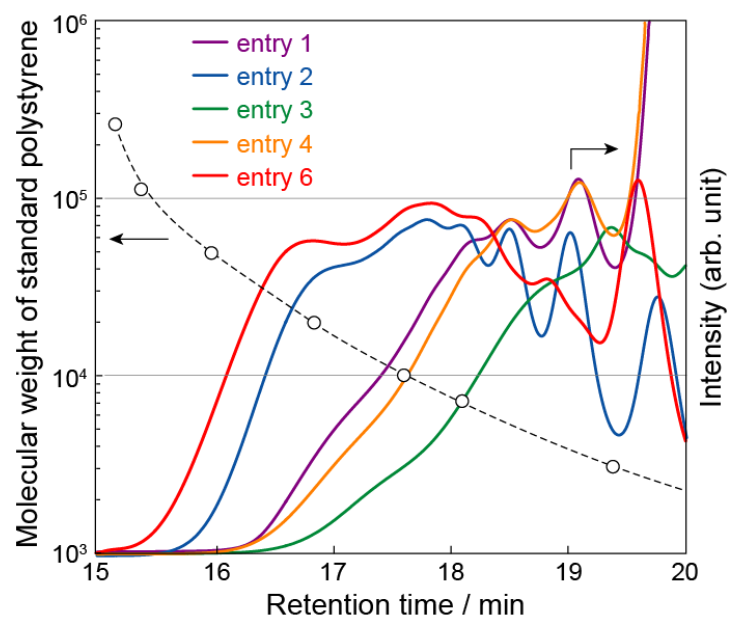

Figure 3. GPC curves of as-prepared polyHE5Ts obtained by polycondensation reactions using direct $\mathrm{C}-\mathrm{H}$ coupling with different reac tion conditions.

Table 1. Reaction conditions of polycondensations using direct C-H couplinga).

\begin{tabular}{|c|c|c|c|c|}
\hline Entry & Pd catalyst ${ }^{\text {b) }}$ & Ligand $^{c)}$ & Base & Solvent \\
\hline 1 & $\mathrm{Pd}(\mathrm{OAc})_{2}$ & $\mathrm{PCy}_{3} \cdot \mathrm{HBF}_{4}$ & $\mathrm{~K}_{2} \mathrm{CO}_{3}$ & Toluene \\
\hline 2 & $\mathrm{Pd}(\mathrm{OAc})_{2}$ & $\mathrm{PCy}_{3} \cdot \mathrm{HBF}_{4}$ & $\mathrm{~K}_{2} \mathrm{CO}_{3}$ & DMAc \\
\hline 3 & $\mathrm{Pd}(\mathrm{OAc})_{2}$ & $\mathrm{PCy}_{3} \cdot \mathrm{HBF}_{4}$ & $\mathrm{~K}_{2} \mathrm{CO}_{3}$ & THF \\
\hline 4 & $\mathrm{Pd}(\mathrm{OAc})_{2}$ & $\mathrm{P} t \mathrm{Bu}_{2} \mathrm{Me} \cdot \mathrm{HBF}_{4}$ & $\mathrm{~K}_{2} \mathrm{CO}_{3}$ & DMAc \\
\hline 5 & Herrman & $\mathrm{PCy}_{3} \cdot \mathrm{HBF}_{4}$ & $\mathrm{~K}_{2} \mathrm{CO}_{3}$ & DMAc \\
\hline 6 & $\mathrm{Pd}(\mathrm{dba})_{2}$ & $\mathrm{P}(o-\mathrm{MeOPh})_{3}$ & $\mathrm{Cs}_{2} \mathrm{CO}_{3}$ & THF \\
\hline
\end{tabular}

a) Reactions were carried out using palladium source ( $5 \mathrm{~mol} \%$ ), ligand (5 mol\%), base (2.0 equiv), and pivalic acid (1.5 equiv) at $0.1 \mathrm{M}$ of monomer concentration at $100{ }^{\circ} \mathrm{C}$ for $24 \mathrm{~h}$; b) $\mathrm{Pd}(\mathrm{OAc})_{2}=$ palladium (II) diacetate, Herrman = trans-bis(acetato)bis[o-(di-o-tolylphosphino)benzyl]dipalladium(II), $\operatorname{Pd}(\mathrm{dba})_{2}=$ bis(dibenzylideneacetone)palladium(0); c) $\mathrm{PCy}_{3} \cdot \mathrm{HBF}_{4}=$ tricyclohexylphosphinetetrafluoroborate, $\mathrm{PtBu}_{2} \mathrm{Me} \cdot \mathrm{HBF}_{4}=$ di(tert-butyl)methylphosphinetetrafluoroborate, $\mathrm{P}(o-\mathrm{MeOPh})_{3}=$ tris(2-methoxyphenyl)phosphine. 
When DMAc was used as a solvent, polyHE5T with the highest molecular weight was obtained (entry 2). It is known that $\mathrm{PtBu}_{2} \mathrm{Me} \cdot \mathrm{HBF}_{4}$ was the best ligand for the polycondensation of 1,2,4,5-tetrafluorobenzene with 2,7-dibromo-9,9-dioctylfluorene [35], while this catalytic system did not promote the polycondensation reaction of 3,3',4,4'-tetramethylbithiophene and 2,7-dibromo-9,9-dioctylfluorene [36]. In our case, the use of $\mathrm{PtBu}_{2} \mathrm{Me} \cdot \mathrm{HBF}_{4}$ (entry 4) did not improve the molecular weight of polyHE5T compared with the case of $\mathrm{PCy}_{3} \cdot \mathrm{HBF}_{4}$ (entry 2). Herrmann's catalyst is also known as an effective catalyst for direct C-H coupling [37]-[39], but polycondensation did not proceed in the current system (entry 5). Very recently, Ozawa et al. reported that the palladium complex with dibenzylideneacetone and $\mathrm{P}(\mathrm{o}-\mathrm{MeOPh})_{3}$, in conjunction with pivalic acid and $\mathrm{Cs}_{2} \mathrm{CO}_{3}$ exhibit high catalyst performance in polycondensation [40] [41]. Using this catalytic system (entry 6), the molecular weight of polyHE5T was slightly improved in comparison with the catalytic system of $\mathrm{Pd}(\mathrm{OAc})_{2}$ and $\mathrm{PCy}_{3} \cdot \mathrm{HBF}_{4}$ (entry 2). Since the resulting polymer was found to be soluble in common organic solvents such as THF, $\mathrm{CHCl}_{3}, \mathrm{DMF}_{\text {, }}$ and $o$-dichlorobenzene, the polymer could be purified by reprecipitation. GPC analysis of polyHE5T obtained by the reaction condition of entry 6 revealed that the molecular weight of the polymer was $M_{\mathrm{n}}=8600, M_{\mathrm{w}}=$ 14,000 and $M_{\mathrm{w}} / M_{\mathrm{n}}=1.6$.

\subsection{Physicochemical Properties of PolyHE5T}

The normalized UV-vis absorption and fluorescence spectra of HE5T and polyHE5T in dilute THF solution are depicted in Figure 4, and their optical properties are summarized in Table 2. Both absorption and fluorescence spectra of polyHE5T were red-shifted compared with those of HE5T due to the expansion of effective $\pi$-conjugation length by the polymerization. It was also found that smooth films of polyHE5T were successfully obtained by spin-coating of its solution in $o$-dichlorobenzene on ITO and/or glass substrate. Using the good film-forming property, it is expected that electrochemical and electrical properties of polyHE5T in film state can be investigated. Their detailed properties will be discussed in the near future.

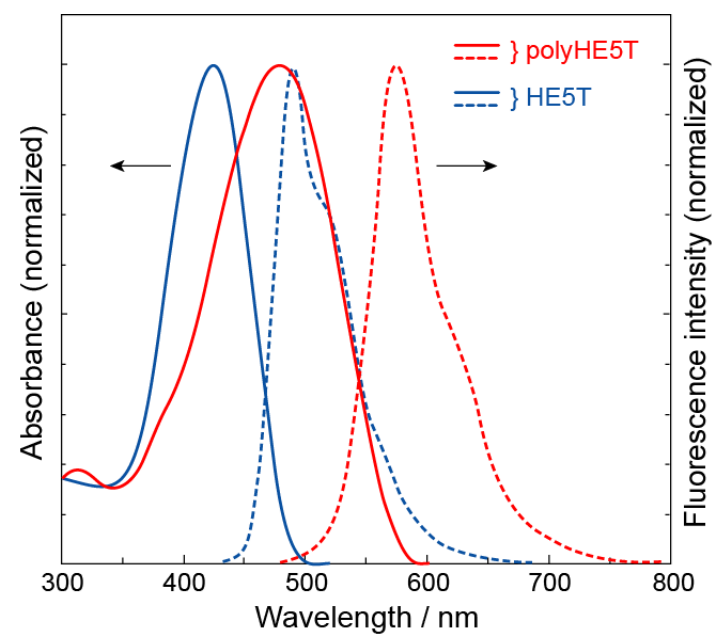

Figure 4. UV-vis absorption (solid line) and fluorescence (dashed line) spectraof polyHE5T (red) and HE5T (blue) in THF solution.

Table 2. Optical properties of HE5T and polyHE5T ${ }^{\text {a) }}$.

\begin{tabular}{ccccc}
\hline & Absorption & & Fluorescence \\
Compound & $\lambda_{\max } / \mathrm{nm}$ & $\log \varepsilon$ & $\lambda_{\max } / \mathrm{nm}$ & \\
\hline HE5T & 425 & 4.65 & $491^{\mathrm{b})}$ & 0.20 \\
polyHE5T & 477 & 4.56 & $575^{\mathrm{c})}$ & 0.28 \\
\hline
\end{tabular}

a) Measured in THF solution (concentration: $10^{-5} \mathrm{~mol} \cdot \mathrm{dm}^{-3}$ (absorption), $10^{-6} \mathrm{~mol} \cdot \mathrm{dm}^{-3}$ (fluorescence); b) excited at $425 \mathrm{~nm}$; c) excited at $477 \mathrm{~nm}$. 


\section{Conclusion}

Polythiophene containing 3,4-ethylenedioxythiophene in a repeat unit was firstly synthesized by polycondensation. Among polycondensation reactions which were tried in this study, direct C-H coupling reaction gave a polymer with the highest molecular weight. The molecular weight of the polymer was further increased by selecting the appropriate condition of catalytic system. Absorption and fluorescence spectra of the resulting polymer were red-shifted in comparison with those of the corresponding monomer reflecting that the effective $\pi$-conjugation length was expanded by the polymerization.

\section{Acknowledgements}

This work was supported in part by grants from the Hiroshima Bank (I.I.), the General Sekiyu Research \& Development Encouragement \& Assistance Foundation (I.I.), the TANAKA Holdings (I.I.) and grants-in-aid for scientific research from the Japan Society for the Promotion of Science (JSPS) (no. 22550198, I.I. and no. 25288085, Y.H.).

The authors are grateful to Dr. Tomoko Amimoto, Dr. Daisuke Kajiya and Dr. Yutaka Mouri, the Natural Science Center for Basic Research and Development (N-BARD), Hiroshima University for the measurement of mass spectroscopy and the elemental analysis.

\section{References}

[1] Skotheim, T.A. and Reynolds, J.R. (Eds.) (2007) Handbook of Conducting Polymers. 3rd Edition, CRC Press, Boca Raton.

[2] Leclerc, M. and Morin, J.F. (Eds.) (2010) Design and Synthesis of Conjugated Polymers. Wiley-VCH, Weinheim. http://dx.doi.org/10.1002/9783527629787

[3] Chujo, Y. (Ed.) (2010) Conjugated Polymer Synthesis: Methods and Reactions. Wiley-VCH, Weinheim. http://dx.doi.org/10.1002/9783527632664

[4] Inzelt, G. (Ed.) (2012) Conducting Polymers: A New Era in Electrochemistry. Springer, Heidelberg. http://dx.doi.org/10.1007/978-3-642-27621-7

[5] Kirchmeyer, S. and Reuter, K. (2005) Scientific Importance, Properties and Growing Applications of Poly(3,4-ethylenedioxythiophene). Journal of Materials Chemistry, 15, 2077-2088. http://dx.doi.org/10.1039/b417803n

[6] Elschner, A., Kirchmeyer, S., Lovenich, W., Merker, U. and Reuter (2010) PEDOT: Principles and Applications of an Intrinsically Conductive Polymer. CRC Press, Boca Raton. http://dx.doi.org/10.1201/b10318

[7] Yan, H. and Okuzaki, H. (2010) Poly(3,4-ethylenedioxythiophen)/Poly(4-styrenesulfonate): Thin Films and Microfibers. Macromolecular Symposia, 296, 286-293. http://dx.doi.org/10.1002/masy.201051040

[8] Elschner, A. and Lövenich, W. (2011) Solution-Deposited PEDOT for Transparent Conductive Applications. MRS Bulletin, 36, 794-798. http://dx.doi.org/10.1557/mrs.2011.232

[9] Yue, R. and Xu, J. (2012) Poly(3,4-ethylenedioxythiophene) as Promising Organic Thermoelectric Materials: A MiniReview. Synthetic Metals, 162, 912-917. http://dx.doi.org/10.1016/j.synthmet.2012.04.005

[10] Matsushita, S., Jeong, Y.S. and Akagi, K. (2013) Electrochromism-Driven Linearly and Circularly Polarized Dichroism of Poly(3,4-ethylenedioxythiophene) Derivatives with Chirality and Liquid Crystallinity. Chemical Communications, 49, 1883-1890. http://dx.doi.org/10.1039/c2cc37116b

[11] Patra, A., Bendikov, M. and Chand, S. (2014) Poly(3,4-ethylenedioxyselenophene) and Its Derivatives: Novel Organic Electronic Materials. Accounts of Chemical Research, 47, 1465-1474. http://dx.doi.org/10.1021/ar4002284

[12] Raimundo, J.M., Blanchard, P., Frère, P., Mercier, N., Ledoux-Rak, I., Hierleb, R. and Roncali, J. (2001) Push-Pull Chromophores Based on 2,2'-Bi(3,4-ethylenedioxythiophene) (BEDOT) $\pi$-Conjugating Spacer. Tetrahedron Letters, 42, 1507-1510. http://dx.doi.org/10.1016/S0040-4039(00)02317-0

[13] Raimundo, J.M., Blanchard, P., Gallego-Planas, N., Mercier, N., Ledoux-Rak, I., Hierle, R. and Roncali, J. (2002) Design and Synthesis of Push-Pull Chromophores for Second-Order Nonlinear Optics Derived from Rigidified Thiophene-Based $\pi$-Conjugating Spacers. The Journal of Organic Chemistry, 67, 205-218. http://dx.doi.org/10.1021/jo010713f

[14] Turbiez, M., Frère, P., Allain, M., Videlot, C., Ackermann, J. and Roncali, J. (2005) Design of Organic Semiconductors: Tuning the Electronic Properties of $\pi$-Conjugated Oligothiophenes with the 3,4-Ethylenedioxythiophene (EDOT) Building Block. Chemistry: A European Journal, 11, 3742-3752. http://dx.doi.org/10.1002/chem.200401058

[15] Spencer, H.J., Skabara, P.J., Giles, M., McCulloch, I., Coles, S.J. and Hursthouse, M.B. (2005) The First Direct Expe- 
rimental Comparison between the Hugely Contrasting Properties of PEDOT and the All-Sulfur Analogue PEDTT by Analogy with Well-Defined EDTT-EDOT Copolymers. Journal of Materials Chemistry, 15, 4783-4792. http://dx.doi.org/10.1039/b511075k

[16] Özen, A.S., Atilgan, C. and Sonmez, G. (2007) Noncovalent Intramolecular Interactions in the Monomers and Oligomers of the Acceptor and Donor Type of Low Band Gap Conducting Polymers. The Journal of Physical Chemistry C, 111, 16362-16371. http://dx.doi.org/10.1021/jp074380n

[17] Hergué, N., Leriche, P., Blanchard, P., Allain, M., Gallego-Planas, N., Frère, P. and Roncali, J. (2008) Evidence for the Contribution of Sulfur-Bromine Intramolecular Interactions to the Self-Rigidification of Thiophene-Based $\pi$-Conjugated Systems. New Journal of Chemistry, 32, 932-936. http://dx.doi.org/10.1039/b802313a

[18] Sotzing, G.A., Reynolds, J.R. and Steel, P.J. (1996) Electrochromic Conducting Polymers via Electrochemical Polymerization of Bis(2-(3,4-ethylenedioxy)thienyl) Monomers. Chemistry of Materials, 8, 882-889. http://dx.doi.org/10.1021/cm9504798

[19] Sotzing, G.A., Reddinger, J.L., Reynolds, J.R. and Steel, P.J. (1997) Redox Active Electrochromic Polymers from Low Oxidation Monomers Containing 3,4-Ethylenedioxythiophene (EDOT). Synthetic Metals, 84, 199-201. http://dx.doi.org/10.1016/S0379-6779(97)80712-6

[20] Johansson, T., Mammo, W., Svensson, M., Andersson, M.R. and Inganäs, O. (2003) Electrochemical Bandgaps of Substituted Polythiophenes. Journal of Materials Chemistry, 13, 1316-1323. http://dx.doi.org/10.1039/B301403G

[21] Pepitone, M.F., Eaiprasertsak, K., Hardaker, S.S. and Gregory, R.V. (2003) Synthesis of 2,5-Bis[(3,4-ethylenedioxy)thien-2-yl]-3-Substituted Thiophenes. Organic Letters, 5, 3229-3232. http://dx.doi.org/10.1021/ol035071s

[22] Andersson, P., Forchheimer, R., Tehrani, P. and Berggren, M. (2007) Printable All-Organic Electrochromic ActiveMatrix Displays. Advanced Functional Materials, 17, 3074-3082. http://dx.doi.org/10.1002/adfm.200601241

[23] Atılgan, N., Cihaner, A. and Önal, A.M. (2010) Electrochromic Performance and Ion Sensitivity of a Terthienyl Based Fluorescent Polymer. Reactive and Functional Polymers, 70, 244-250. http://dx.doi.org/10.1016/j.reactfunctpolym.2009.12.006

[24] Invernale, M.A., Ding, Y. and Sotzing G.A. (2010) All-Organic Electrochromic Spandex. ACS Applied Materials \& Interfaces, 2, 296-300. http://dx.doi.org/10.1021/am900767p

[25] Imae, I., Imabayashi, S., Korai, K., Mashima, T., Ooyama, Y., Komaguchi, K. and Harima, Y. (2012) Electrosynthesis and Charge-Transport Properties of Poly(3',4'-ethylenedioxy-2,2':5',2'-terthiophene). Materials Chemistry and Physics, 131, 752-756. http://dx.doi.org/10.1016/j.matchemphys.2011.10.046

[26] Inzelt, G. (2012) Chemical and Electrochemical Syntheses of Conducting Polymers. In: Inzelt, G., Ed., Conducting Polymers: A New Era in Electrochemistry, Springer, Heidelberg, 149-172. http://dx.doi.org/10.1007/978-3-642-27621-7_4

[27] Bhattacharyya, D., Howden, R.M., Borrelli, D.C. and Gleason, K.K. (2012) Vapor Phase Oxidative Synthesis of Conjugated Polymers and Applications. Journal of Polymer Science Part B: Polymer Physics, 50, 1329-1351. http://dx.doi.org/10.1002/polb.23138

[28] Darmanin T. and Guittard, F. (2014) Wettability of Conducting Polymers: From Superhydrophilicity to Superoleophobicity. Progress in Polymer Science, 39, 656-682. http://dx.doi.org/10.1016/j.progpolymsci.2013.10.003

[29] Yamamoto, T. (2010) Organometallic Polycondensation for Conjugated Polymers. In: Chujo, Y., Ed., Conjugated Polymer Synthesis: Methods and Reactions, Wiley-VCH, Weinheim, 1-34. http://dx.doi.org/10.1002/9783527632664.ch1

[30] Tamao, K., Kodama, S., Nakajima, I. and Kumada, M. (1982) Nickel-Phosphine Complex-Catalyzed Grignard Coupling-II. Tetrahedron, 38, 3347-3354. http://dx.doi.org/10.1016/0040-4020(82)80117-8

[31] Hoffmann, K.J. and Carlsen P.H.J. (1999) Study of an Efficient and Selective Bromination Reaction of Substituted Thiophenes. Synthetic Communications, 29, 1607-1610. http://dx.doi.org/10.1080/00397919908086142

[32] Meng, H., Perepichka, D.F. and Wudl, F. (2003) Facile Solid-State Synthesis of Highly Conducting Poly(ethylenedioxythiophene). Angewandte Chemie International Edition, 42, 658-661. http://dx.doi.org/10.1002/anie.200390181

[33] Liégault, B., Lapointe, D., Caron, L., Vlassova, A. and Fagnou K. (2009) Establishment of Broadly Applicable Reaction Conditions for the Palladium-Catalyzed Direct Arylation of Heteroatom-Containing Aromatic Compounds. The Journal of Organic Chemistry, 74, 1826-1834. http://dx.doi.org/10.1021/j08026565

[34] Lapointe, D., Markiewicz, T., Whipp, C.J., Toderian, A. and Fagnou, K. (2011) Predictable and Site-Selective Functionalization of Poly(hetero)arene Compounds by Palladium Catalysis. The Journal of Organic Chemistry, 76, 749759. http://dx.doi.org/10.1021/jo102081a

[35] Lu, W., Kuwabara, J. and Kanbara, T. (2011) Polycondensation of Dibromofluorene Analogues with Tetrafluorobenzene via Direct Arylation. Macromolecules, 44, 1252-1255. http://dx.doi.org/10.1021/ma1028517

[36] Fujinami, Y., Kuwabara, J., Lu, W., Hayashi, H. and Kanbara, T. (2012) Synthesis of Thiophene- and Bithiophene- 
Based Alternating Copolymers via Pd-Catalyzed Direct C-H Arylation. ACS Macro Letters, 1, 67-70. http://dx.doi.org/10.1021/mz200067s

[37] Wang, Q., Takita, R., Kikuzaki, Y. and Ozawa, F. (2010) Palladium-Catalyzed Dehydrohalogenative Polycondensation of 2-Bromo-3-hexylthiophene: An Efficient Approach to Head-to-Tail Poly(3-hexylthiophene). Journal of the American Chemical Society, 132, 11420-11421. http://dx.doi.org/10.1021/ja105767z

[38] Wang, Q., Wakioka, M. and Ozawa, F. (2012) Synthesis of End-Capped Regioregular Poly(3-hexylthiophene)s via Direct Arylation. Macromolecular Rapid Communications, 33, 1203-1207. http://dx.doi.org/10.1002/marc.201200076

[39] Berrouard, P., Najari, A., Pron, A., Gendron, D., Morin, P.O., Pouliot, J.R., Veilleux, J. and Leclerc, M. (2012) Synthesis of 5-Alkyl[3,4-c]thienopyrrole-4,6-dione-Based Polymers by Direct Heteroarylation. Angewandte Chemie International Edition, 51, 2068-2071. http://dx.doi.org/10.1002/anie.201106411

[40] Wakioka, M., Kitano, Y. and Ozawa, F. (2013) A Highly Efficient Catalytic System for Polycondensation of 2,7-Dibromo-9,9-dioctylfluorene and 1,2,4,5-Tetrafluorobenzene via Direct Arylation. Macromolecules, 46, 370-374. http://dx.doi.org/10.1021/ma302558z

[41] Wakioka, M., Ichihara, N., Kitano, Y. and Ozawa, F. (2014) A Highly Efficient Catalyst for the Synthesis of Alternating Copolymers with Thieno[3,4-c]pyrrole-4,6-dione Units via Direct Arylation Polymerization. Macromolecules, 47, 626-631. http://dx.doi.org/10.1021/ma4023668 
Scientific Research Publishing (SCIRP) is one of the largest Open Access journal publishers. It is currently publishing more than 200 open access, online, peer-reviewed journals covering a wide range of academic disciplines. SCIRP serves the worldwide academic communities and contributes to the progress and application of science with its publication.

Other selected journals from SCIRP are listed as below. Submit your manuscript to us via either submit@scirp.org or Online Submission Portal.
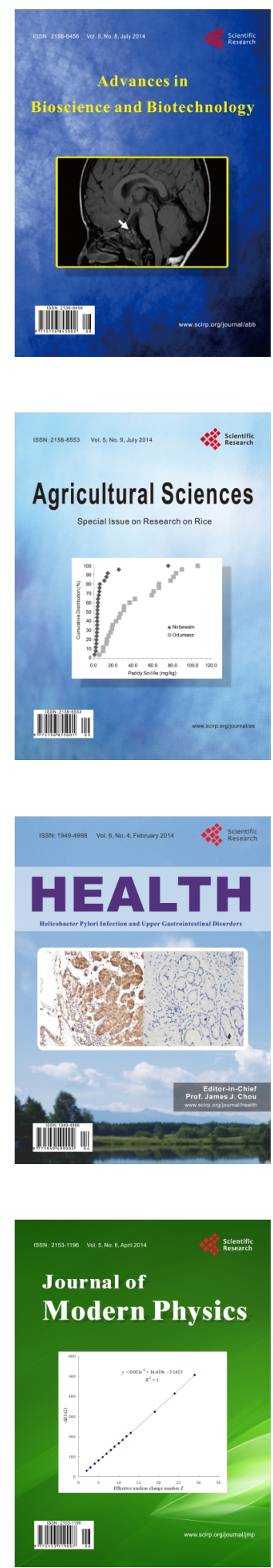
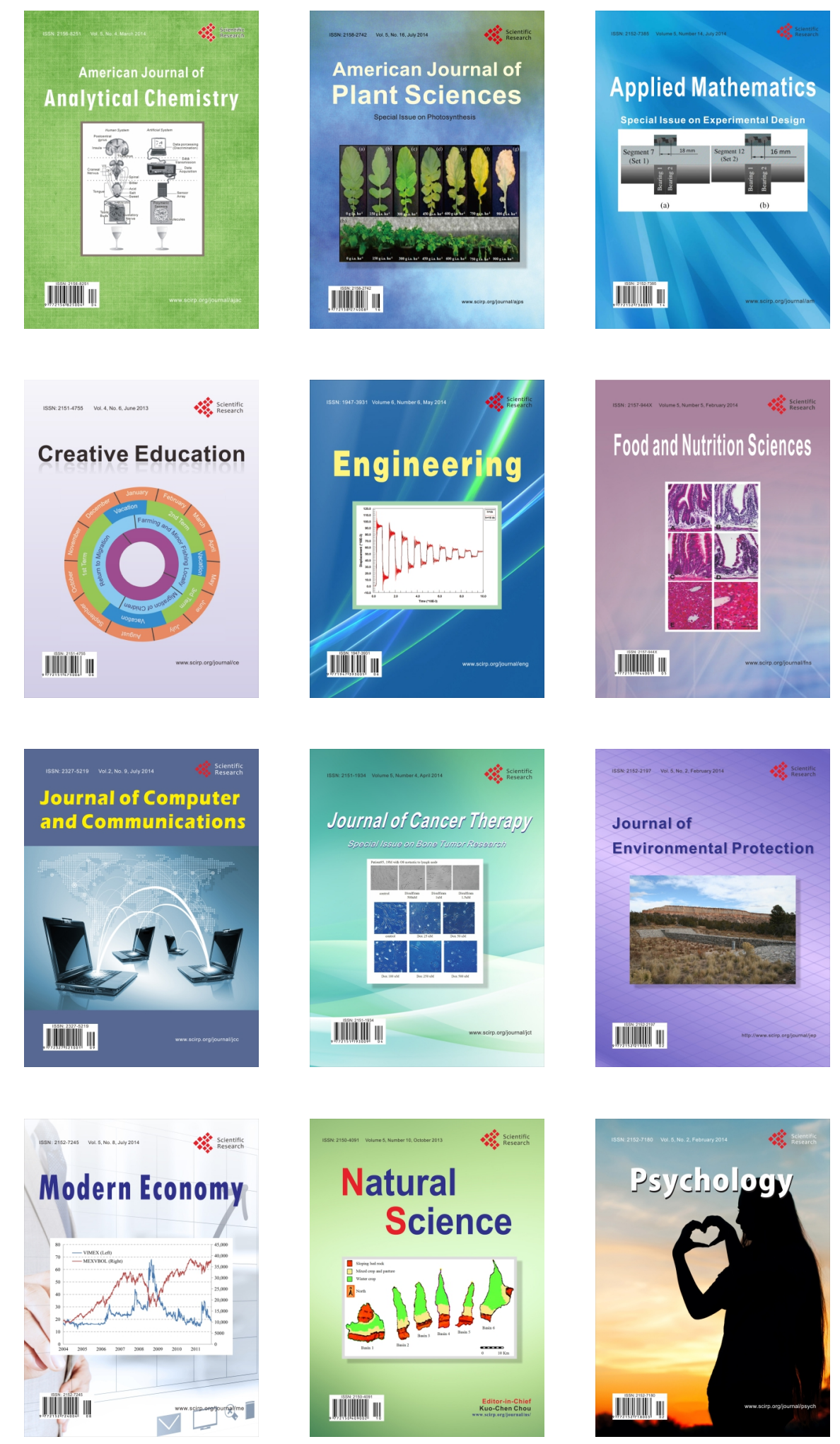